\title{
GAMBARAN STRES PADA MAHASISWA PENDIDIKAN PROFESI PROGRAM STUDI KEDOKTERAN GIGI FAKULTAS KEDOKTERAN UNIVERSITAS SAM RATULANGI YANG MEMILIKI PENGALAMAN STOMATITIS AFTOSA REKUREN
}

\author{
Viniriani Tangkilisan \\ Prof. dr. P. L. Suling, MSc, SpKK(K) ${ }^{1}$, drg. Christy Mintjelungan, MKes ${ }^{2}$ \\ Program Studi Kedokteran Gigi Fakultas Kedokteran Univeristas Sam Ratulangi Manado \\ Email : vinitangkilisan9128@yahoo.com
}

\begin{abstract}
Stomatitis Aftosa Rekuren (SAR) merupakan kelainan ulkus pada mukosa mulut dengan ciri khas ulkus single atau multiple, kambuhan (berulang), kecil, bulat atau oval dengan batas jelas kemerahan dan dasar abu-abu atau kuning. Stomatitis Aftosa Rekuren dapat dipicu oleh beberapa faktor predisposisi antara lain stres, trauma, alergi, genetik, siklus menstruasi, defisiensi hematinik dan imunologi.

Tujuan dalam penelitian ini ialah untuk mengetahui gambaran stress pada mahasiswa pendidikan profesi Program Studi Kedokteran Gigi Fakultas Kedokteran Universitas Sam Ratulangi yang memiliki pengalaman Stomatitis Aftosa Rekuren. Metode penelitian yang digunakan yaitu penelitian deskriptif dengan penelitian studi cross sectional. Metode pengambilan sampel yaitu purposive sampling. Sampel pada penelitian ini berjumlah 62 orang. Cara pengambilan data mengisi kuesioner SAR dan PSS (Perceived Stress Scale) dengan wawancara.

Hasil penelitian menunjukan bahwa gambaran stres pada mahasiswa pendidikan profesi Program Studi Kedokteran Gigi Fakultas Kedokteran Universitas Sam Ratulangi yang memiliki pengalaman Stomatitis Aftosa Rekuren sebesar 59,7\% dengan tingkat stres yang tinggi.
\end{abstract}

Kata Kunci : SAR, tingkat stres

Recurrent aphthous stomatitis (RAS) is an ulcer on the oral mucosal abnormalities characterized by a single or multiple ulcers, recurrent (repeated), a small, round or oval with clear boundaries and basic reddish gray or yellow. RAS can be triggered by several predisposing factors such as stress, trauma, allergies, genetic, menstrual cycle and immunological deficiency haematinics.

The purpose of this study was overview the stress on professional education student of Dentistry Program Medical Faculty, University of Sam Ratulangi. The research method used is descriptive research with a cross- sectional study design. Sampling method by purposive sampling. Samples in this study amounted to 62 people. The data were collected through questionnaires SAR and PSS (Perceived Stress Scale).

The results showed that the description of stress on professional education students of Dentistry Program Medical Faculty, University of Sam Ratulangi experiencing SAR by $59.7 \%$ with high level of stress.

Keywords: SAR, stress level

Stomatitis Aftosa Rekuren (SAR) merupakan penyakit pada mukosa mulut yang paling sering diderita manusia dengan ciri khas ulkus single atau multiple, kambuhan (berulang), kecil, bulat atau oval dengan batas jelas kemerahan dan dasar abu- 
abu atau kuning. Pada umumnya prevalensi SAR sekitar 25-60\% dari populasi dunia. ${ }^{1,2}$ Beberapa negara telah melaporkan angka kejadian SAR seperti Amerika Serikat $(60 \%)$, Swedia (2\%), Spanyol $(1,9 \%)$, dan Malaysia $(0,5 \%)$, sedangkan di Indonesia belum ada data yang pasti mengenai angka kejadian SAR. ${ }^{3}$

Prevalensi SAR bervariasi tergantung usia dan jenis kelamin. SAR lebih sering dijumpai pada wanita daripada pria. Menurut Smith dan Wray, SAR dapat terjadi pada semua kelompok umur tetapi lebih sering ditemukan pada masa dewasa muda. ${ }^{3}$ Etiologi SAR yang pasti hingga saat ini belum diketahui dengan jelas. Ulkus pada SAR dapat dipicu oleh beberapa faktor, salah satu faktor yang dapat memicu terjadinya SAR yaitu stres. ${ }^{4,5}$

Menurut beberapa penelitian, prevalensi SAR pada mahasiswa kedokteran dan kedokteran gigi di Amerika sebesar 55\% dan prevalensi SAR dipicu stres pada mahasiswa kedokteran dan kedokteran gigi sebesar $66 \% .^{3,6}$ Menurut penelitian yang dilakukan Argy pada mahasiswa pendidikan profesi kedokteran gigi di Athena tahun 2005 menunjukkan bahwa mahasiswa pendidikan profesi cenderung mengalami stres yang berhubungan dengan kesulitan dalam memenuhi kebutuhan klinis sebelum diijinkan melakukan pemeriksaan. ${ }^{7,8}$

Berdasarkan survei awal, diketahui sebagian mahasiswa pendidikan profesi Program Studi Kedokteran Gigi Fakultas Kedokteran cenderung mengalami stres dan pernah mengalami SAR. Berdasarkan latar belakang di atas, peneliti tertarik untuk melakukan penelitian tentang bagaimana gambaran stres pada mahasiswa pendidikan profesi Program Studi Kedokteran Gigi Fakultas Kedokteran Universitas Sam Ratulangi yang memiliki pengalaman Stomatitis Aftosa Rekuren.

\section{METODE PENELITIAN}

Jenis penelitian ini ialah penelitian deskriptif dengan menggunakan pendekatan cross sectional (potong lintang), dimana semua data diobservasi sekali pada saat yang bersamaan. Penelitian ini dilakukan pada bulan Juli 2013 di Balai Pengobatan Rumah Sakit Gigi dan Mulut Manado. Sampel pada penelitian diperoleh dengan menggunakan rumus Slovin dimana populasi subyek yang diteliti kurang dari $10.000:{ }^{9}$

$\boldsymbol{n}=\frac{\mathbf{N}}{\mathbf{N}(\mathbf{d})^{2}+\mathbf{1}}$

keterangan :

$\mathrm{n}=$ jumlah sampel

$\mathrm{N}=$ jumlah unit populasi

$\mathrm{d}=$ margin kesalahan, diambil 0,1

Berdasarkan rumus yang ada, maka dapat diperoleh data hasil sebagai berikut:

$$
\mathrm{n}=\underbrace{}_{166(0,1)^{2}+1}=62,40=62
$$

Besar sampel yang digunakan ialah sebanyak 62 responden dengan metode pengambilan sampel purposive sampling, yang telah memenuhi kriteria inklusi. Kriteria inklusi yaitu responden bersedia diwawancara, bersifat kooperatif dan pernah mengalami stomatitis (sariawan) minimal 2 kali sedangkan kriteria eksklusi dalam penelitian ini yaitu responden sedang sakit dan responden menggunakan kawat gigi (alat ortodontik) dan gigi tiruan (prostodontik). Penelitian ini menggunakan Kuesioner Stomatitis Aftosa Rekuren (SAR) dan Kuesioner Perceived Stress Scale (PSS). 


\section{HASIL PENELITIAN}

Responden dalam penelitian ini yaitu mahasiswa yang sedang menjalani kepaniteraan klinik di BP-RSGMP Manado dan yang berpartisipasi dalam mengisi kuesioner sebanyak 62 orang. Terdapat 37 orang $(59,7 \%)$ yang memiliki tingkat stres tinggi. (tabel 1)

Diperoleh 9 orang laki-laki $(14,5 \%)$ dan 28 orang perempuan $(45,2 \%)$ yang masuk dalam kategori tingkat stres tinggi. (tabel 2) karakteristik responden yang mengalami SAR berdasarkan umur dibagi dalam 4 kelompok yaitu kelompok umur 1820 tahun, 21-23 tahun, 24-26 tahun dan 2729 tahun. Dari hasil p enelitian, responden yang memiliki pengalaman SAR dengan tingkat stres tinggi paling banyak didapatkan pada kelompok umur 24-26 tahun $(61,3 \%)$ dan responden yang memiliki pengalaman SAR dengan tingkat stres rendah terdapat pada kelompok umur 21-23 tahun $(6,4 \%)$. (tabel 3)

Tabel 1. Distribusi frekuensi tingkat stres pada responden.

\begin{tabular}{lcc}
\hline Tingkat Stres & $\mathrm{n}$ & $\begin{array}{c}\text { Presentase } \\
(\%)\end{array}$ \\
\hline Rendah & 5 & 8.0 \\
Normal & 20 & 32.3 \\
Tinggi & 37 & 59.7 \\
Total & 62 & 100.0 \\
\hline
\end{tabular}

Tabel 2. Distribusi frekuensi tingkat stres responden berdasarkan jenis kelamin

\begin{tabular}{|c|c|c|c|c|c|c|c|c|c|c|}
\hline \multirow[t]{3}{*}{ Jenis kelamin } & \multicolumn{6}{|c|}{ Tingkat Stres } & \multicolumn{4}{|c|}{ Total } \\
\hline & \multicolumn{2}{|c|}{ Rendah } & \multicolumn{2}{|c|}{ Normal } & \multicolumn{2}{|c|}{ Tinggi } & \multicolumn{2}{|c|}{ Sangat Tinggi } & \multirow[b]{2}{*}{$\mathrm{n}$} & \multirow[b]{2}{*}{$\%$} \\
\hline & $\mathrm{n}$ & $\%$ & $\mathrm{n}$ & $\%$ & $\mathrm{n}$ & $\%$ & $\mathrm{n}$ & $\%$ & & \\
\hline Laki-laki & 2 & 3.2 & 6 & 9.7 & 9 & 14.5 & 0 & 0.0 & 17 & 27.4 \\
\hline Perempuan & 3 & 4.8 & 14 & 22.6 & 28 & 45.2 & 0 & 0.0 & 45 & 72.6 \\
\hline Total & 5 & 8.1 & 20 & 32.3 & 37 & 59.7 & 0 & 0.0 & 62 & 100.0 \\
\hline
\end{tabular}


Tabel 3. Distribusi frekuensi tingkat stres responden berdasarkan umur

\begin{tabular}{lcccccccccc}
\hline Umur & \multicolumn{1}{c}{ Tingkat Stres } & \multicolumn{4}{c}{ Total } \\
& \multicolumn{1}{c}{ Rendah } & \multicolumn{2}{c}{ Normal } & \multicolumn{2}{c}{ Tinggi } & \multicolumn{3}{c}{ Sangat Tingi } & \multicolumn{2}{c}{ n } \\
& $\mathrm{n}$ & $\%$ & $\mathrm{n}$ & $\%$ & $\mathrm{n}$ & $\%$ & $\mathrm{n}$ & $\%$ & $\mathrm{n}$ & $\%$ \\
\hline $18-20$ & 0 & 0.0 & 0 & 0.0 & 0 & 0.0 & 0 & 0.0 & 0 & 0.0 \\
$21-23$ & 4 & 6.4 & 8 & 12.7 & 11 & 17.7 & 0 & 0.0 & 23 & 37.1 \\
$24-26$ & 1 & 1.6 & 12 & 22.6 & 25 & 40.3 & 0 & 0.0 & 38 & 61.3 \\
$27-29$ & 0 & 0.0 & 0 & 0.0 & 1 & 1.6 & 0 & 0.0 & 1 & 1.6 \\
Total & 5 & 8.1 & 20 & 32.3 & 37 & 59.7 & 0 & 0.0 & 62 & 100.0 \\
\hline
\end{tabular}

\section{PEMBAHASAN}

Stomatitis Aftosa Rekuren merupakan ulkus berbentuk oval pada mukosa mulut yang di tandai secara berulang tanpa disertai dengan penyakit lain dan merupakan salah satu kondisi yang paling menyakitkan pada mukosa mulut terutama sewaktu makan, menelan dan berbicara. Menurut penelitian yang dilakukan oleh Polychronopoulou A. dkk, mahasiswa kedokteran gigi memiliki prevalensi SAR yang tinggi dan cenderung mengalami stres. ${ }^{10,11}$ Stres merupakan tekanan atau kecemasan yang disebabkan oleh masalah dalam kehidupan seseorang dan berat atau ringannya stres yang dialami oleh seseorang dapat diukur dengan Perceived Stress Scale (PSS).

Berdasarkan data yang didapatkan pada tabel 1, terdapat 37 orang $(59,7 \%)$ yang mengalami SAR dan masuk dalam kategori tingkat stres tinggi. Hal ini mendeskripsikan bahwa kecenderungan stres pada mahasiswa pendidikan profesi Program Studi Kedokteran Gigi Fakultas Kedokteran cukup besar. Tingginya tingkat stres yang dirasakan dikalangan mahasiswa kedokteran gigi ini sering dikaitkan dengan tekanan psikologis dan kelelahan emosi. Hasil ini memperkuat penelitian yang dilakukan oleh Kumar, et al (2011) di India, bahwa mahasiswa pendidikan profesi cenderung mengalami stres yang berhubungan dengan kesulitan dalam memenuhi kebutuhan klinis sebelum melakukan pemeriksaan di klinik. Hal ini menyebabkan tekanan beban kerja yang berat sehingga mahasiswa sering merasa takut gagal dan khawatir akan tertinggal dalam persyaratan khusus yang harus di penuhi di klinik. ${ }^{12}$

Berdasarkan data yang terdapat pada tabel 2, dapat dilihat bahwa dari 62 orang yang menjadi responden penelitian terdapat 28 orang $(45,2 \%)$ perempuan yang mengalami SAR dan memiliki tingkat stres tinggi dan 9 orang $(14,5 \%)$ laki-laki yang mengalami SAR dan memiliki tingkat stres tinggi. Hasil ini menunjukkan responden perempuan yang mengalami SAR memiliki tingkat stres tinggi yang lebih besar daripada responden laki-laki. Hal ini serupa dengan penelitian yang di lakukan oleh Baldwin yang menyatakan tingkat stres yang tinggi lebih besar di alami oleh perempuan daripada laki-laki, dimana perempuan lebih peka terhadap lingkungannya dan lebih mudah mengalami beban psikis seperti cemas dan merasa tidak senang. ${ }^{12}$ Mahasiswa perempuan sering mengalami stres yang lebih tinggi daripada mahasiswa laki-laki. Masalah yang sering ditemukan 
pada mahasiswa perempuan adalah berkaitan dengan kepercayaan diri, memperoleh keterampilan klinis dan memenuhi persyaratan akademik. ${ }^{13}$

Berdasarkan data yang terdapat pada tabel 3 dapat dilihat responden yang mengalami SAR paling banyak didapatkan pada kelompok umur 24-26 tahun $(61,3 \%)$. Hal ini serupa dengan penelitian yang dilakukan Smith dan Wray menyatakan bahwa SAR dapat terjadi pada semua kelompok umur tetapi lebih sering ditemukan pada masa dewasa muda. ${ }^{8}$ Hal serupa juga di kemukakan dalam penelitian oleh Aida di Surabaya pada tahun 2009 yang menyatakan bahwa pada orang dewasa kondisi mukosa rongga mulut akan berubah, seperti keratinisasi menurun sehingga akan menyebabkan volume saliva menurun (mukosa mulut akan terasa kering) dalam hal ini mukosa mulut akan lebih sensitif terhadap iritasi dan cedera. ${ }^{4}$ SAR paling sering dimulai selama dekade kedua dari kehidupan seseorang., ${ }^{8,13}$ Menurut Axell prevalensi tertinggi SAR tejadi pada kelmpok umur 15-25 tahun. $^{14}$

Berdasarkan hasil pengukuran tingkat stres menunjukkan bahwa responden yang mengalami stres tinggi paling banyak terdapat pada responden yang berumur 2426 tahun. Hal ini sesuai dengan literatur yang menyatakan bahwa mahasiswa pendidikan profesi yang berumur sekitar 1825 tahun sedang mengalami masa penyesuaian diri terhadap pola kehidupan mereka yang baru, dan merupakan masa peralihan dari masa remaja ke masa dewasa. $^{13}$

\section{KESIMPULAN}

Berdasarkan hasil penelitian, maka dapat diambil kesimpulan bahwa :

1. Mahasiswa pendidikan profesi Program Studi Kedokteran Gigi Fakultas
Kedokteran Universitas Sam Ratulangi yang memiliki tingkat stres tinggi yaitu sebesar $59,7 \%$ dan yang memiliki tingkat stres rendah sebanyak $8,0 \%$.

2. Gambaran stres pada mahasiswa pendidikan profesi berdasarkan jenis kelamin paling banyak ditemukan pada perempuan sebanyak 28 orang perempuan $(45,2 \%)$ dengan tingkat stres yang tinggi.

3. Gambaran stres pada mahasiswa pendidikan profesi yang berdasarkan umur paling banyak ditemukan pada mahasiswa kelompok umur 24-26 tahun dengan tingkat stres sebesar $61,3 \%$ dan yang memiliki pengalaman SAR dengan tingkat stres rendah terdapat pada kelompok umur 21-23 tahun $(6,4 \%)$.

\section{SARAN}

Perlu dilakukan penelitian yang lebih lanjut tentang hubungan SAR dengan faktor predisposisi lainnya.

\section{DAFTAR PUSTAKA}

1. Scully C, de Almeida OP, Bagan J, Dioz PD, Taylor AM. Oral Medicine and Pathology at a Glance. West Sussex: Wiley-Blackwell. 2010; p. 56-7.

2. Gallo CB, Mimura MAM, Sugaya NN. Psychological stress and recurrent aphthous stomatitis. Clinics. 2009;64(7):645-8.

3. Jurge S, Kuffer R, Scully C, Porter SR. Mucosal disease series Nmber IV. Recurrent aphthous stomatitis . Oral Dis 2006;12:1-21.

4. Rosarina A, Hendarti H.T, Soenartyo H. Prevalensi stomatitis aftosarekuren (SAR) yang dipicuoleh stress psikologis: di Klinik Penyakit Mulut Psgm Fkg Unair September-oktober 2009. O Me Dent Journal. 2009;1;2:42-5 
5. Boras VV, Savage NW. Recurrent Aphtous Ulcerative Disease: Presentation and Management. Aust Dent Journal. 2007; 52 (1): 10-5.

6. Scully C. Aphtous Ulceration. N Engl J Med [serial online]. 2006 [cited $2012 \mathrm{Feb}$ 08]; 355 (2): 165-72. Available from: http://www.nejm.org/doi/full/10.1056/NE JMcp054630.

7. Nally M. I.M. Recurrent aphthous stomatitis and perceived stress (a preliminary study). (23 Agustus 2010). (http://apthousstressutdy.tripod.com/html)

8. Polychronopoulou A, Divaris K. Perceived Sources of Stress Among Greek Dental Students. J Dent Educ 2005;69(6):687-692.

9. AS Kumar, S Kumar, S Abraham, PSS Rao, Leprosy Among Tribal Population of Chhattisgarh state India, New Delhi, Indian J. Leer 2011,83;23-29 (25.01.2011) (http://www.Ijl.org.in)

10. Srinivas Rao P. Recurrent Aphtous Stomatitis: A Review. J Orofac Sci. 2010; 2(3): 60-5

11. Hurlbutt M, Thomsen L. Demystifying Recurrent Oral Ulcerations. ADA CERP PennWell [serial online]. 2007 [cited 2012 May 23]; 4: $\quad 1-9 . \quad$ Availablefrom: http://www.ineedce.com/courses/1430/P DF/DemystRecurOralUlceratns.pdf

12. Nasir A, Muhith A, Ideputri ME. Buku Ajar: Metodologi Penelitian Kesehatan. Yogyakarta: Nuha Medika. 2011; h. 185-210

13. Nasution IK. Stres pada remaja. USU Repository; Medan: 2007.

14. Scully $\mathrm{C}$ and Felix DH. Oral medicine : update for the dental practioner, Aphthous and other common ulcers. Br Dent J 2005; 1995 (5):259-264 